\title{
Clinical presentation and prevalence of uterine fibroids: a 3-year study in 3-decade rural South Indian women
}

\author{
Mohanambal M. Munusamy, Wills G. Sheelaa*, Vijaya P. lakshmi
}

\begin{abstract}
Department of Obstetrics and Gynecology, Shri Sathya Sai Medical College and Research Institute, Ammapettai,
\end{abstract} Kanchipuram district, Tamil Nadu, India

Received: 23 September 2017

Accepted: 27 October 2017

\section{*Correspondence:}

Dr. Wills G. Sheelaa,

E-mail: drgwillssheelaa@yahoo.in

Copyright: () the author(s), publisher and licensee Medip Academy. This is an open-access article distributed under the terms of the Creative Commons Attribution Non-Commercial License, which permits unrestricted non-commercial use, distribution, and reproduction in any medium, provided the original work is properly cited.

\begin{abstract}
Background: Uterine fibroids are benign tumors arising from smooth muscle cells of myometrium. This study was conducted in rural women belonging to poor socio-economic class and primary school dropouts to find out clinical presentation, prevalence of uterine fibroids, their knowledge about health services and to develop modalities to improve awareness and early reporting to prevent morbidity and improve quality of life.

Methods: Women ranging from 26-55 years age attending Gynecology OPD of SSSMCRI for abdominopelvic mass, pain, menstrual abnormalities over a period of 3 years were registered for the study. Socio-demographic profile, detailed menstrual history, reason for attending hospital and previous treatment taken prior to the hospital visit were recorded. Women with pregnancy with fibroids and fibroids detected by ultra-sonogram less than 12 weeks were excluded from the study. Clinical, local and ultra-sonographic examination was done for the morphology of the fibroids. Comparison was done with histological picture for accuracy in clinical and sonographic diagnosis.

Results: 362 women who presented with uterine fibroids, menorrhagia or with abdomino pelvic mass were registered for this study. Of 136 patients who had uterine fibroids $66 \%$ had menorrhagia with severe anemia, $23 \%$ needed blood transfusion, 17 were nulliparous women. Menorrhagia was the commonest menstrual pattern seen in 58.8\% women. Asymptomatic fibroids with huge abdomino pelvic mass was seen in 46 women (33\%). The size was 12-28 weeks. The mean age was 46 years. Abdominal hysterectomy was done in 88 women, and 3 in-situ hysterectomies (91 cases) $(67 \%)$, polypectomy in 16 and myomectomy in 22 nulliparous women. Laparotomy for torsion sub-serous fibroids was done in 7.

Conclusions: Further research is needed to find out biological factors causing fibroids including diet, stress, environmental and racial influences. Routine screening, early detection, increase awareness by early reporting to the hospital will reduces morbidity and improves quality of life socioeconomically.
\end{abstract}

Keywords: Abdomino pelvic mass, Anemia, Coexisting adenomyosis, Menorrhagia, Uterine fibroids

\section{INTRODUCTION}

Uterine fibroids are slow growing, benign tumors that arises from smooth muscle cell of the uterus. ${ }^{1}$ One third of Gynecology admissions are fibroids with menorrhagia, anaemia and lump in the abdomen with pain. ${ }^{2}$ Growth of leiomyoma is dependent on estrogen production, especially continuous estrogen secretion when uninterrupted by pregnancy and lactation, it is thought to be the most important risk factor for the development of myomatous fibroid. ${ }^{2}$ Fibroids occurs in $20-40 \%$ of women during reproductive age and $11-19 \%$ in perimenopausal age. ${ }^{2}$ In many women uterine fibroids are found incidentally, on routine gynaecological 
examination or on pelvic imaging performed for unrelated symptoms like infertility, pain and lump in the abdomen. ${ }^{3}$ The site-size-numbers vary from one woman to another. Microscopic as well as giant-size fibroids have been reported in the literature.

The slow growing asymptomatic fibroids are seen more frequently in $30 \%$ of multiparous women belonging to perimenopausal age. ${ }^{4}$ They attain huge size without causing menstrual symptoms. Most of these are intramural which are confined to myometrium. Symptomatic fibroids are seen in 35-55 years age group. Mean age was 40 and women presented with menorrhagia, metrorrhagia, pain and multiple sub mucous fibroids, which distort the myometrial cavity. Women attending Gynecology OPD with heavy gushing type of bleeding, long menses and number of hospital visits were careseekers with symptomatic fibroids were 14-16 weeks fibroids who needed medical/surgical intervention. ${ }^{5}$ These women presented with severe anemia, pain from degenerative changes. ${ }^{5}$ Fibroids increase in size as women grow older and cause pressure symptoms and majority needed surgical interventions like hysterectomy or myomectomy. ${ }^{1,2,6}$

These factors cause negative impact on health care seekers $(33 \%)$ with severe dysmenorrhoeal and bleeding PV had co existing adenomyosis. ${ }^{6,7}$ They had more pain despites smaller fibroids which were ultrasound detected tumor less than 12 weeks in the age group of 30-40 years. ${ }^{7}$ Women who failed conservative management for heavy bleeding with pelvic pain had coexisting adenomyosis. Women who present with sub-fertility and unexplained infertility, had coexisting uterine myomas who needed myomectomy not responding to medical treatment. ${ }^{8}$ Frequent visit to hospital for heavy bleeding $\mathrm{PV}$ and pain, not responding to treatment, have profound negative impact on life emotionally and socio economically.

In the present study the prevalence rate was $37.65 \%$, in Bombay 24\%, Peshwar (Pakistan) $78 \%$ and Nigeria $29.3 \% .5,6,8$ There is huge disparity in the sociodemographic profile for uterine fibroids with respect to geographic and racial profile. ${ }^{9}$ Prevalence was $37.65 \%$ in rural setup, $24 \%$ in urban Bombay, $78 \%$ in Peshawar and $29.3 \%$ in Nigeria. Even though uterine fibroids are benign, they are associated with morbidity in $40 \%$ women affecting their quality of life. Hence further research should be done to find out etiological clues in factors like diet, stress, environmental and racial influences in development of uterine fibroid. By creating awareness, early detection of tumors and proper guidance for treatment will reduce morbidity and improve quality of health.

\section{METHODS}

This was a prospective hospital based observational study. It was conducted in Shri Sathya Sai hospital and
Medical college, surrounded by villages in the suburban silk city of India, Kanchipuram. Study was conducted for 3 years from 2014-2016 in women belonging to 3 decades of life from 26-55 years. All women who attended Gynecology OPD with complaints of menstrual disorders with anemia or abdomino-pelvic mass with pain and feeling heaviness in the abdomen were registered for the study.

\section{Exclusion criteria}

Women with fibroid and pregnancy, USG diagnosed fibroids less than 12 weeks were excluded from the study. Aim was to find out clinical presentation and prevalence of uterine fibroids in rural population, and formulate modalities to improve awareness and report early for treatment.

Preoperative assessment was done by taking detailed history regarding age, parity, diet, geography and race, previous menstrual pattern, reason for seeking medical care and the treatment taken prior to this hospital visit. Their knowledge and attitude and application of knowledge for available health services were noted, as most of them presented late with severe anemia and abdomino-pelvic mass. In all patient's, routine investigations like blood group and Rh-typing, $\mathrm{HB} \%$, RBS and urine analysis was done. Local, clinical and bimanual pelvic examination was done along with pelvic sonogram for morphology of tumor. Patients were clinically observed from date of admission till discharge and follow-up.

Post-operative assessment was done by comparing histology of operative specimens and clinical, ultrasonogram findings for accuracy of diagnosis and prevalence of fibroids, their type and clinical presentation. In this study clinical, sonographical, histological correlative accuracy was 90\%. All 136 women needed surgical intervention, of that $23 \%$ needed more than one blood transfusion. Results were analyzed for formulating modalities to improve quality of health for early referral to tertiary centers for management.

\section{RESULTS}

362 women were admitted over a period of 3 years in SSSMCRI in the age group of 25-55 years for the complaints of menstrual abnormalities with anemia or abdomino pelvic mass with pain for treatment were considered for prospective observational hospital based study. Ultra-sonogram diagnosed small fibroids less than 12 weeks and uterine fibroids with pregnancy was excluded from the study. Preoperative assessment from history, clinical examination, ultrasonogram finding was compared with postoperative histological findings for accuracy in diagnosis and morphology of uterus. Out of 362 women prevalence of uterine fibroids was only $37.65 \%$. 
Table 1: Clinical presentation: asymptomatic fibroid-46.

\begin{tabular}{|c|c|c|c|}
\hline $\begin{array}{l}\text { Clinical } \\
\text { findings }\end{array}$ & $\begin{array}{l}\text { No. of } \\
\text { patients }\end{array}$ & Presentation & $\%$ \\
\hline $\begin{array}{l}\text { Abdomino } \\
\text { pelvic mass }\end{array}$ & 46 & $\begin{array}{l}\text { Feeling of fullness } \\
\text { of abdomen }\end{array}$ & 34.8 \\
\hline $\begin{array}{l}\text { Feeling of } \\
\text { heaviness }\end{array}$ & 25 & $\begin{array}{l}\text { Heaviness of } \\
\text { abdomen, lump in } \\
\text { the abdomen }\end{array}$ & 18.1 \\
\hline Uterus size & $\mathrm{N}=46$ & & \\
\hline 13-20 weeks & 21 & Palpable mass & 15 \\
\hline 21-24 weeks & 16 & $\begin{array}{l}\text { Abdomino pelvic } \\
\text { mass }\end{array}$ & 11 \\
\hline $\begin{array}{l}\text { More than } \\
24 \text { weeks }\end{array}$ & 9 & Pain & $7 \%$ \\
\hline
\end{tabular}

46 women presented with abdomino pelvic mass without menstrual abnormality. Average size was 20 weeks. Largest was 32 weeks. In a 42-year-old nulliparous woman who came for confirmation of pregnancy. More than one mortality was seen in $10 \%$ women. Postoperative diagnosis was single intramural fibroid of weight $3.2 \mathrm{~kg}$.

Table 2: Clinical presentation: symptomatic fibroids-90.

\begin{tabular}{|l|l|}
\hline Clinical findings & $\begin{array}{l}\text { No. of } \\
\text { patients }\end{array}$ \\
\hline Anemia & 92 \\
\hline Dysmenorrhea & 34 \\
\hline Aub & 71 \\
\hline Lump in the abdomen (14 - 20 weeks) & 46 \\
\hline Mass protruded through cervix & 16 \\
\hline Cervical fibroids with retention of urine & 13 \\
\hline $\begin{array}{l}\text { Anterior abdomen torsion of } \\
\text { pedunculated subserous fibroid }\end{array}$ & 07 \\
\hline
\end{tabular}

Women $(66 \%)$ presented with severe anaemia due to menorrhagia. Women with polymenorrhagia (33.4\%) presented with palpable abdomio pelvic masses ranging from 13-28 weeks.

The largest was 32 weeks intra mural fibroid weighing about $3.8 \mathrm{~kg}$. 16 women presented with fibroid polyp and metrorrhagia. 13 had retention of uterus due to cervical fibroid, laparotomy in 7 women who presented with acute abdominal pain. Intra operative diagnosis was torsion of pedunculated subserous fibroid more than 1 morbidity was seen in $40 \%$ women

Out of 136 women 92 were $(68 \%)$ anaemic, 48 women (38\%) needed preoperative blood transfusion. 32 (23\%) needed more than one blood transfusion. Lowest $\mathrm{HB}$ in this study was $3.2 \mathrm{~g} \%$ in a woman of 38 years with 14 weeks submucosal fibroid uterus with leiomyomatous polyp. She had polymenorrhagia which was not responding to treatment. Insitu hysterectomy was done. Menorrhagia was seen in 53 women (58.8\%).

Moderate to heavy bleeding was seen in women with intramural fibroid. Excessive bleeding with clots was seen $22.2 \%$ (20) women who had multiple subserous fibroids. $16(18 \%)$ women who had leiomyomatous submucous polyps had metrorrhagia and polymenorrhea.

USG detected small fibroids with adenomyosis, patients had moderate flow with severe dysmenorrhea. Subserous pedunculated fibroid was seen in 7 who had normal menstruation with a palpable lump in the abdomen.

Table 3: Prevalence of anaemia.

\begin{tabular}{|ll|}
\hline Haemoglobin & Number of patients \\
\hline$<5 \mathrm{~g}$ & 12 \\
\hline $6-7 \mathrm{~g}$ & 20 \\
\hline $8-9 \mathrm{~g}$ & 60 \\
\hline$>9$ & 44 \\
\hline
\end{tabular}

88 women had abdominal hysterectomy for uterine fibroids in peri-menopausal age group. 3 had insitu hysterectomy for submucous leiomyomatous polyp of size $6 \times 4 \mathrm{~cm}$ with thick pedicle arising from the fundus which could not be removed vaginally $\{n=91(67 \%)\}$. Polypectomy was done in 16 women $(11.5 \%)$ in the reproductive age, who presented with polymenorrhagia and metrorrhagia.

Myomectomy was done in $22(16.3 \%)$ who presented with infertility. Laparotomy was done in 7 women $(5 \%)$ who presented with acute abdominal pain. Intra operative finding was torsion of pedunculated subserous fibroid.

Table 4: Correlation of menstrual pattern with various types of fibroid $\mathbf{n}=\mathbf{9 0}$.

\begin{tabular}{|llll|}
\hline Type of fibroid & Number & Menstrual pattern & Percentage \\
\hline Intramural single non-mucosal fibroid & 33 & Moderate to heavy bleeding & 36.6 \\
\hline Submucosal multiple fibroid & 20 & Heavy bleeding with clots & 22.2 \\
\hline Leiomyomatous submucosal polyp & 16 & Metrorrhagic polymenorrhagia & 18 \\
\hline Seedling fibroid with adenomyosis & 14 & Moderate flow with severe dysmenorrhoeal & 15.5 \\
\hline Sub serous pedunculated fibroid & 7 & Normal menstruation & 7.7 \\
\hline
\end{tabular}


Table 5: Management.

\begin{tabular}{|lll|}
\hline Management & Number & Percentage \\
\hline Uterus removed & $\mathrm{N}=91$ & 67 \\
\hline Abdominal hysterectomy & 88 & \\
\hline $\begin{array}{l}\text { Insitu hysterectomy with } \\
\text { leiomyomatous polyp }\end{array}$ & 3 & \\
\hline Conservative surgery & $\mathrm{N}=45$ & 33 \\
\hline Myomectomy & 22 & 16.3 \\
\hline Polypectomy & 16 & 11.7 \\
\hline $\begin{array}{l}\text { Laparotomy for torsion } \\
\text { submucous fibroid }\end{array}$ & 7 & 5 \\
\hline
\end{tabular}

\section{Histology findings}

$90 \%$ accuracy was seen in correlation between USG and post hysterectomy histological findings. Out of 8 Adenomatous hyperplasia reported by USG, 4 were submucosal fibroid polyps hystologically. Adenomyosis with coexisting small fibroids was seen in 21 specimens instead of 14 reported ultra sonologically. Out of 24 multiple submucosal fibroids reported by USG there were 6 broad ligament fibroids histologically.

\section{Table 6: Correlation between USG finding and histological finding.}

\begin{tabular}{|lll|}
\hline USG finding & $\begin{array}{l}\text { Number- } \\
\text { USG }\end{array}$ & $\begin{array}{l}\text { Number- } \\
\text { histology }\end{array}$ \\
\hline Single intra mural & 53 & 50 \\
\hline Multiple submucosal & 24 & 19 \\
\hline Adenomatous hyperplasia & 8 & 4 \\
\hline Submucous fibroid polyp & 16 & 16 \\
\hline Subserous fibroid & 7 & 7 \\
\hline $\begin{array}{l}\text { Adenomyosis with seedling } \\
\text { fibroid }\end{array}$ & 14 & 21 \\
\hline Cervical, & 13 & 13 \\
\hline Broad ligament fibroid & 1 & 6 \\
\hline
\end{tabular}

Table 7: Socio-demographic characteristics and prevalence.

\begin{tabular}{|c|c|c|c|c|c|c|}
\hline Age & Number & Percentage & Parity & Number & Education & Prevalence \\
\hline $25-35$ & 9 & 7 & Nulliparous & 27 & School drop outs in primary school & Sssmch-37.65\% \\
\hline $36-45$ & 105 & 77 & Para 1 & 65 & School drop outs in primary school & Rawalpindi-78\% \\
\hline $46-55$ & 22 & 16 & Para 2 & 8 & School drop outs in primary school & $\begin{array}{l}\text { Numba1- } 24 \% \\
\text { Nigeria-29.3\% }\end{array}$ \\
\hline
\end{tabular}

Table 7 shows socio demographic characteristics and prevalence of uterine fibroids. It varies with geographical and racial influences. The risk factors are diet, stress, hormonal. Highest incidence was seen in Pakistani women $78 \%$, then rural Indian women $37.65 \%$, urban India $24 \%$ and Nigerian women $30 \%$. Arobosoba from Nigeria has reported prevalence of uterine fibroids in black women was more $(26 \%)$, in comparison to Caucasian women (17.9\%). Age distribution was similar in all studies. Mean age was 46. Maximum uterine fibroids were seen in premenopausal women. Prevalence of coexisting uterine fibroids in sub-infertility, undiagnosed infertility was $40 \%$ in Atombosoba's study. The prevalence of benign lesions in uterine fibroid specimens suggest huge disparity ranging from $6-55 \%$.

\section{DISCUSSION}

Uterine fibroids are slow growing benign tumors arising from smooth muscle cells of the myometrium. Slow growing asymptomatic fibroids grow to huge size with minimal menstrual disturbances. ${ }^{4}$ They often present with pressure symptoms in multiparous women. Most of these are intra mural fibroids which are confined to the myometrium. Often the patient reports with feeling of heaviness of abdomen and lower abdominal pain. ${ }^{4}$ Table 1 shows clinical presentation of asymptomatic fibroids in 46 women $(36 \%)$ with abdomino pelvic mass varying from 13-28 weeks, average size was 20 weeks, who presented with complaints of abdominal pain and feeling of heaviness of abdomen. Menstrual cycle was not affected in these women. In the present study 25 women complained of pain and backache. The largest fibroid we operated was 32 weeks size, intramural fibroid in a 42 year-old nulliparous patient weighing $3.5 \mathrm{~kg}$. This lady came to the hospital to confirm pregnancy. USG diagnosed small fibroids less than 12 weeks fibroids were excluded from the study. In the study by Faiza in Pakistani women from Rawalpindi, intramural asymptomatic fibroid were seen in 23.1 percentage in women who presented with abdominal pain. ${ }^{4}$ Prevalence of uterine fibroids was 77.14 percentage in their study which is very high.

Table 2 shows clinical presentation of symptomatic fibroids in 90 women. These were submucosal fibroids who presented as multiple fibroids or leiomyomatous polyps, which distort the myometrial cavity. These women presented with gushing type of bleeding and long menses associated with pain and Metrorrhagia. In this study 46 women (33.4\%) had multiple fibroids, 16 women had polyps (11.8\%) which protruded through external OS, 3 had fundal leiomyomatous fibroid polyps with thick pedicle which could not be removed vaginally. $78 \%$ of these presented with severe anemia, who needed blood transfusions. In a study conducted in Bombay, 
Rajeshwari reported $30 \%$ of her study subjects, had symptomatic fibroids who presented with metrorrhagia. ${ }^{5}$ Shagufta's study in Pakistani women from Peshawar, the incidence was $78.99 \%$ where $75 \%$ women presented with menorrhagia and anemia. ${ }^{6}$ Her observation was, fibroids increase in size as women grow older and often present with pressure symptoms. ${ }^{6}$ In the present study 13 women reported with recurrent episodes of retention of urine who had cervical fibroids of size 16-20 weeks. Dysmenorrhea was seen in women similar to authors. ${ }^{5,6}$ Laparotomy was done in 7 women for torsion of pedunculated subserous fibroids in the present study.

Table 3 shows hemoglobin status at the time of admission. Out of 136 women admitted for uterine fibroids $68 \%(\mathrm{~N}=82)$ were anemic, 48 women $(38 \%)$ needed blood transfusion and $32(23.5 \%)$ more than 1 blood transfusion. Lowest hemoglobin percentage recorded in our study was $3.2 \%$ in a woman with 14 weeks fibroid with large $6 \times 4 \mathrm{~cm}$ leiomyomatous submucosal polyp with thick pedicle. In a study by Shagufta in Peshawar observed that $33.61 \%$ of her patients had severe anemia due to abnormal uterine bleeding who needed repeated blood transfusions. ${ }^{6}$ Most of her patients were from younger age group from 31-40 years.

Table 4 shows correlation of menstrual pattern with various types of uterine fibroids. Moderate to heavy bleeding was seen in 33 women $(36.6 \%)$ within the mural fibroids. Gushing type of heavy bleeding was seen in 20 women $(22.2 \%)$ with submucous multiple fibroids. Polymenorrhea and metrorrhagia was seen in $16(18 \%)$ women who had leiomyomatous submucosal polyp. Moderate flow with severe pain was seen in 14 women $(15.5 \%)$ with adenomyosis. No menstrual change was noted in subserosal fibroids. ${ }^{7}$ Various authors have reported that menorrhagia was the commonest menstrual pattern in symptomatic submucosal fibroids $(38.9 \%)$ by Faiza $78 \%$ by Rajeshwari and Shagufta (36.6\%) of thier subjects. ${ }^{4-6}$ Metrorrhagia and polymenorrhea was seen in observations made by the same authors in $25.9 \%$ by Faiza, $10 \%$ of Rajeshwari's subjects. ${ }^{8}$ Many authors have reported that menorrhagia was the most common menstrual pattern with symptomatic submucosal fibroids. ${ }^{4-6}$ Taran A has reported $33 \%$ of his subjects had adenomyosis with leiomyoma presented with pelvic pain. He observed that women who had severe pelvic pain despite smaller fibroids detected by sonogram more likely to have concomitent adenomyosis. In this series 14 women $(10 \%)$ had adenomyosis coexisting with leiomyoma who presented with severe pelvic pain with moderate bleeding.

All 136 women had surgical intervention irrespective of age and parity (Table 5). Abdominal hysterectomy was done in 88 women in perimenopausal age. Insitu hysterectomy was done in 3 where Leiomyomatous submucosal polyp could not be removed vaginally. Myomectomy in $22(16.3 \%)$, nulliparous women were incidentally diagnosed while investigating for infertility. Polypectomy in 16 in reproductive age group, laparotomy for torsion of submucosal fibroid in 7 (38\%). Risk to operative interference in women presenting with abdominopelvic mass, multiple fibroids, adenomyosis is very high. ${ }^{8}$

90\% accuracy was seen in correlation between USG and post-operative histological findings (Table 6). Adenomatous hyperplasia reported by sonogram in 8 cases were adenomatous polyp histologically. Adenomyosis with seedling fibroids was seen in 21 histological specimens instead of 14 sonological diagnosis. Pathological findings in hysterectomy, specimens reported my Sajrad M from Pakistan shows uterine fibroids and adenomyosis were the common abnormality detected. ${ }^{10}$ In her study in $22 \%$ cases no gross or microscopic abnormality was detected.

Table 7 shows prevalence of uterine fibroids which varies with geographical and racial influences. Risk factors are diet, stress, hormonal and environmental factors. There was a difference in incidence in rural India (37.65\%) and urban India $(24 \%)$ women. Incidence in Pakistani women was $78 \%$. Atombosoba from Nigeria has reported that incidence in black women was more $26 \%$ than in Caucasians (17.9\%). $77 \%$ of our study subjects belonged to $36-48$ age group, Nullipara with fibroids were $27 \%$ in the age group of 26-35 years. Mean age affected was 46 in all studies. All our study subjects belonged to low socioeconomic class and were primary school dropouts rural women with no knowledge of available health services.

\section{CONCLUSION}

This is a prospective hospital based observational study conducted in SSSMCRI at Ammapettai in 3-decade age group rural women for 3 years. 362 women who attended Gynec OPD for heavy menses with anaemia or abdominopelvic mass with pain were registered for the study. Mean age of presentation was 46. 136 women were treated for uterine fibroids. Symptomatic fibroids presented with palpable mass, menorrhagia and anaemia. Asymptomatic fibroids presented with huge abdominopelvic mass.

Largest was 32 weeks size. 14 women who did not respond to conservative treatment for severe pain and bleeding had adenomyosis coexisting with small fibroids. Ultrasonogram detected fibroids less than 12 weeks and uterine fibroids with pregnancy were excluded. $20 \%$ women investigated for sub fertility and unexplained infertility had small fibroids. 58.8\% women suffered with Menorrhagia and 33\% needed more than 1 unit of blood. All 136 women had surgical intervention $(n=91) 67 \%$ abdominal hysterectomy 88, insitu hysterectomy 3 . Uterus was preserved in 45 women. Accuracy was $90 \%$ in correlation with clinical, sonological, histological findings. 
Women presented to hospital late with menorrhagia or huge abdomino pelvic mass. All our study subjects belonged to poor socioeconomic class, primary school dropouts, rural women with poor knowledge of available health services. Although a benign tumor, uterine fibroids are associated with more than one morbidity in $40 \%$ women. Prevalence of fibroid in the present study was $37.65 \%$ which varies with age, diet, stress, environmental, racial influences. More research should be done to find out etiological clues in factors causing fibroids for early detection. Early referral to hospital will reduce morbidity and improve quality of life socioeconomically.

\section{ACKNOWLEDGMENTS}

Authors would like to acknowledge the help rendered by Dr. T. Suhilan, Dr. R. Sriram, Dr. P. Srivathsa Junior residents in the Deptartment of $\mathrm{OBG}$ for helping in publishing the this paper.

Funding: No funding sources

Conflict of interest: None declared

Ethical approval: The study was approved by the Institutional Ethics Committee

\section{REFERENCES}

1. Gloria A, Bachmann MD, Linda A, Bahouth BA, Amalraj P, Mhamunkar V, et al. Correlation of anemia and pain to fibroid location and uterine weight. J Reprod Med. 2011;56:463-6.

2. Garg R. Two uncommon presentation of cervical fibroids. People's J Sci Res. 2012;5(2).

3. Mavrelos D, Be-Nagi J, Holland T, Whoo W, Naftalin J, Jurkovic D. The natural history of fibroids. Ultrasound Obstet Gynecol. 2010;35:23842 .
4. Ibrar F, Raiza S, Dawood NS, Jabeen A. Frequency of fibroid uterus in multipara women in a tertiary care centre in Rawalpindi. J Ayub Med Coll Abbottabad. 2010; 22(3):155-7.

5. Khyade RL. A study of menstrual disturbance in cases of fibroid uterus. Int J Reprod Contracept, Obstet Gynecol. 2017;6(6):2494-7.

6. Shaheen S, Naheed T, Sadaf F, Rahim R; Menorrhagia due to fibroids and its management. JSOGP. 2013;3(4):231-5.

7. Taran FA, Weaver AL, Coddington CC, Stewart EA. Characteristics indicating adenomyosis coexisting with leiomyomas: a case-control study. Human Reprod. 2010;25(5):1177-82.

8. Atombosoba A, Ekine, Lawani LO, Iyoke CA, Jeremiah I, Ibrahim IA. Review of clinical presentation of uterine fibroids and the effect of therapeutic intervention on fertility. Am J Clin Med Res. 2015;3(1):9-13.

9. Koothan V, Vijay A, Maran G, Lakshmy S. Prevelence and burden of adenomyosis in hysterectomy specimen for benign abnormal uterine bleeding in a tertiary care institute in Pondicherry, India. Int Jo Reprod Contacept Obstet Gynecol. 2016;5(4):1119-23.

10. Sajjad M, Iltaf S, Qayyum S. Pathological findings in hysterectomy specimens of patients presenting with menorrhagia in different age groups. Ann Pak Inst Med Sci 2011;7(3):160-2.

Cite this article as: Munusamy MM, Sheelaa WG, Lakshmi VP. Clinical presentation and prevalence of uterine fibroids: a 3-year study in 3-decade rural South Indian women. Int J Reprod Contracept Obstet Gynecol 2017;6:5596-601. 